Bažant, Z.P., Pijaudier-Cabot, G., and Pan, J.-Y. (1987). "Ductility, snapback, size effect and redistribution in softening beams and frames." ASCE J. of Structural Engrg. 113 (12), 2348-2364.

\title{
Ductility, Snapback, Size Effect, and Redistribution in Softening Beams or Frames
}

\author{
By Zdenék P. Bažant, Fellow, ASCE,1 Gilles Pijaudier-Cabot; ${ }^{2}$ Student \\ Member, ASCE, and Jiaying Pan ${ }^{3}$
}

\begin{abstract}
Aвsтяаст: A layered finite element model with strain-softening material properties, whose applicability to reinforced concrete was corroborated by comparisons with experimental data in the preceding paper, is used in a parametric study aimed at the effect of several factors: structure size, finite element size, downward slope of strain-softening stress-strain relation, length of the plastic yield plateau before the onset of strain softening (if any), and end-restraint stiffness. To quantify the response, several new response characteristics are introduced: the ductile strengthening factor, characterizing how strain softening reduces the maximum load compared to the plastic limit load; the redistribution ratio, characterizing the degree of bending moment redistribution in comparison to that in plastic limit analysis; the energy safety factor, describing the energy to deform the structure to the peak load; and the ductility factor, characterizing the deflection increase at maximum load relative to the deflection from elastic analysis. The condition of snapback instability, which determines the ductility factor, is derived analytically for an elastically restrained beam. Finally, it is shown that strain-softening segments in beams cannot be modeled as softening hinges except for sufficiently slender beams.
\end{abstract}

\section{INTRODUCTION}

Even though the presence of strain softening in reinforced concrete beams or frames invalidates the use of plastic-limit analysis, inelastic design cannot be abandoned since the elastic allowable stress design would be uneconomic and would not provide a uniform safety margin. It is generally recognized that some degree of inelastic redistribution of bending moments in a statically indeterminate beam or frame should be allowed even when the inelastic behavior involves softening (1). However, the question as to how much moment redistribution can be allowed safely has not been studied systematically. This question, as well as related questions of suitable measures of ductility and inelastic reserve capacity, will be systematically studied in this paper. To quantify the behavior, several new measures of inelastic behavior in presence of softening will be proposed.

The effect of structure size, previously well documented in fracture analysis of strain softening materials (5-9), will also be studied analytically, and so will spurious sensitivity to the finite element size. Finally, the

Prof. of Civ. Engrg., Northwestern Univ., Evanston, IL 60208.

${ }^{2}$ Grad. Res. Asst., Northwestern Univ., Evanston, IL 60208; on leave from Laboratoire de Mécanique et Technologie, Cachan, France.

${ }^{3}$ Visiting Scholar at Northwestern Univ., Evanston, IL 60208; on leave from China Academy of Railway Sciences, Beijing, China.

Note. Discussion open until May 1, 1988. Separate discussions should be submitted for the individual papers in this symposium. To extend the closing date one month, a written request must be filed with the ASCE Manager of Journals. The manuscript for this paper was submitted for review and possible publication on November 4, 1986. This paper is part of the Journal of Structurat Engineering, Vol. 113, No. 12, December, 1987. CASCE, ISSN 0733-9445/87/0012-2348/\$01.00. Paper No. 22021. 
collapse at deflections beyond the peak-load state will be subjected to stability analysis using the method proposed by the first writer in 1974 (4).

Reinforced concrete beams that exhibit softening, whose theoretical analysis is the objective of the present paper, have been analyzed from various viewpoints by a number of researchers, especially Schnobrich et al. $(28,19)$, Scordelis et al. (20), Maier et al. (21-25), Mróz (26), Darvall (14-17), Warner (29), and Wood (30). The present study extends the preceding paper in this issue (10) and uses the same layered finite element model as well as the same notations.

\section{Model Structure and Solution Method}

To study various influences, we consider a symmetric single-span beam with symmetric elastic restraints of spring constant $C$, loaded by a concentrated load $P$ at midspan. To permit analysis of the postpeak response, displacement increments at midspan are prescribed and the load, $P$, is solved as a reaction. Due to symmetry, we need to analyze only one-half of the beam shown in Fig. 1 $(a)$. Later on, we study also an identical but reinforced beam shown in Fig. $1(b)$. The material of the beam is assumed to have strain-softening properties, characterized by one of the
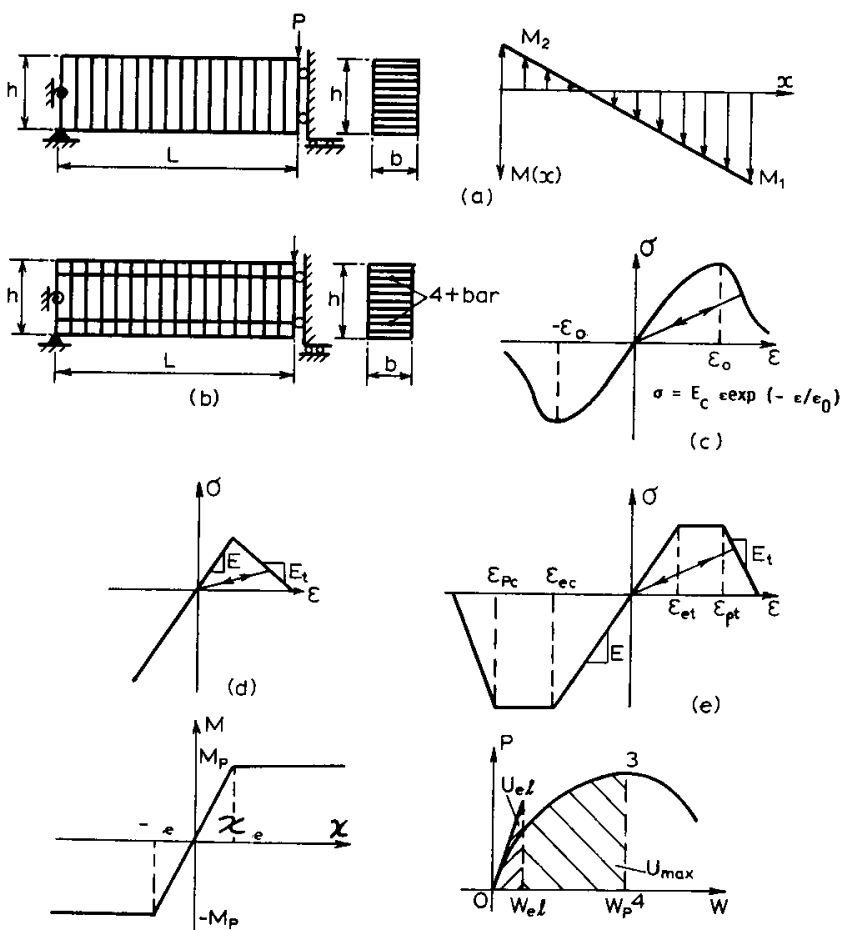

(g)

FIG. 1. (a) Concrete and (b) Reinforced Concrete Beams Analyzed; (o-e) StressStrain Curves for Concrete; (f) Simplified Moment-Curvature Diagram; (g) Definition of Elastic and Maximum Works on Load-Displacement Curve uniaxial stress-strain diagrams shown in Figs. $1(c-e)$. The diagram in Fig. $1(d)$ is hypothetical, used only for theoretical purposes, while the diagrams in Figs. 1 $(c, e)$ may be thought to approximate the behavior of concrete in tension and in compression. In the reinforced beam [Fig. 1(b)], the reinforcement is considered to be elastic-perfectly plastic.

For the purpose of analysis, the half-beam length is subdivided into $N$ identical beam finite elements, and each finite element is further subdivided into 10 layers shown in Figs. $1(a-b)$. The layers are constrained to conform to the standard assumption that the cross-sections remain plane and normal to the deflection line. The steel reinforcement, if any, is represented by a separate steel layer. It is assumed that there is no bond slip between steel and concrete. All the computations are based on the layered finite element model defined in Appendix I of the preceding paper (10), and the numerical step-by-step algorithm, in which very small increments of load-point displacements $w$ are prescribed, consists of the direct iteration method (iterative secant stiffness algorithm) as described in the preceding paper. This algorithm has been converging well in the softening regime, although it does not permit calculation of possible snapback instabilities.

Unloading for concrete is assumed to occur always in the secant direction, along a straight line, and the same line is followed at reloading up to the virgin curve. For steel, the unloading and reloading (if any) is elastic, based on a constant elastic modulus of steel, $E_{s}$ [Figs. $1(a-g)$ ]. The formula for the curved stress-strain diagram is given in Fig. 1(c).

\section{Effects of Structure Size and Element Size}

As argued in the initial 1974 study (4), the element length $L_{e}$ must not be shorter than both: (1) Approximately three maximum aggregate sizes, as concluded in the crack-band theory (9); and (2) the beam depth $h$. The second condition is a consequence of the assumption of plane cross sections underlying the theory, and in practice it always governs. At the same time, to capture the effect of full curvature localization, the minimum element length allowed by the preceding conditions must be used in the softening regions of beams.

To study the effect of the beam size, we consider beams of the same depth but various lengths, i.e., we vary the beam slenderness at constant depth $h$. The finite elements are identical for all the beams, and the beam length is proportional to the number of elements.

Fig. 2(a) shows the calculated load-deflection diagrams in a nondimensional form. The load $P$ is normalized with respect to $P_{0}^{e l}$ representing the load at which the tensile strength $f_{t}^{\prime}$ is just reached if the beam is considered as elastic, with the initial elastic modulus $E_{c}$. The deflections are normalized with respect to the elastic deflection under the load $P_{0}^{e l}$. The calculations are done for spring constant $C=2 E I / L$ and for curved stress-strain diagrams from Fig. 1(c).

The values of the peak loads for Fig. 2(a) are collected in Fig. 2(c) to plot the dependence of the maximum load upon the number, $N$, of elements per half-span. The two separate peaks of the load-deflection diagram in Fig. 2(a) correspond to softening in two separate hinging regions, first the midspan and then the beam ends. 

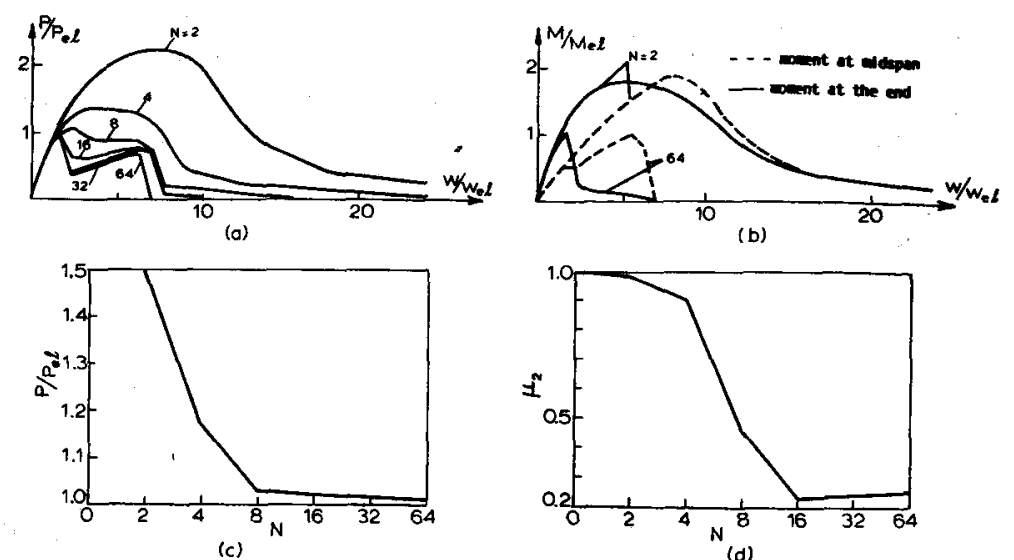

FIG. 2. (a) Nondimensionalized Load-Deflection and (b) Moment-Curvature Curves for Different Meshes; $(a-d)$ Influence of Mesh Refinement on Maximum Load and Redistribution Ratio $\mu_{2}$

According to the known solutions for an elastic material, elastichardening plastic material, and elastic-perfectly plastic material, all the relative responses should be identical, regardless of beam length $2 L$, except for a small numerical error due to the finite size of elements [Fig. $2(c)]$. We see, however, that in presence of strain softening, the relative load-deflection diagrams are not identical. The relative peak load $P / p_{0}^{e l}$ diminishes as the beam length $L$ increases. The nominal stress at peak load, which is defined by $\sigma_{N}=1.5 P L / b h^{2}$, also decreases as $L$ increases ( $b=$ beam width). The coefficient 1.5 is chosen for convenience since $\sigma_{N}$ then corresponds to the plastic limit load; in principle any value can be used for this coefficient. This kind of effect contradicts plastic limit analysis and is typical of fracture mechanics, as discussed elsewhere (4).

The decrease of ductility with increasing slenderness, as apparent from Figs. $2(a-d)$ is typical for strain-softening problems. It was demonstrated analytically for uniaxial tests, as well as beams, already by 1974 (4). Both the ductility decrease and the peak-load decrease at increasing slenderness are connected to the fact that, in a larger structure, there is more energy available for release into the curvature-localization zone.

The shape of the response curves in Fig. 2(a) also varies with the beam's size. The sharp vertical drops in the response curves apparently represent states that are close to the snapback instability (known to occur when the drop of the load-deflection diagram becomes vertical). At these sharp drops, the convergence was very slow, and the loading step could not be made too small since a finite jump onto the post-snapback curve had to be made.

Fig. 2(b) shows similar results for the diagrams of the relative bending moment at midspan versus the relative deflection. For elastic-plastic behavior, these diagrams would have to be also identical.

The area under the complete load-deflection diagram represents the energy dissipation due to failure of the beam. As we see from Fig. 2(a), this energy diminishes as the slenderness increases. Fig. $2(c)$ shows how the peak load tends toward the elastic load $P_{0}^{e l}$. For infinite slenderness, for which the peak load approaches $P_{0}^{e l}$, the ratio of the energy dissipated by failure of the beam to the maximum elastic energy approaches zero. This is clear from the fact that, as the ratio of the element size to the beam length vanishes, the ratio of the volume of the strain-softening zone to the beam volume tends toward zero, while the energy dissipated in the softening material remains finite per unit volume.

Clearly, treating the element length as a beam property dependent on the size of the beam cross section is the only way to obtain objective results: Otherwise, the analysis results would exhibit a spurious effect of the element size due to strain softening. This approach is similar to the way in which the crack-band theory circumvents the inobjectivity of the classical smeared cracking approach in finite element analysis. At the same time, it should be kept in mind that fixing the element length is, of course, an approximate expedient, since without the possibility of refining the element size to zero, one does not have an underlying continuum model, which the discretization is supposed to approximate. However, similar to the concept of nonlocal continuum $(8,12)$, it is possible to avoid this drawback by formulating a nonlocal bending theory, as demonstrated in Ref. 27.

\section{Simple Response Characteristics of Strain-Softening Structures}

It is helpful to first consider the behavior of our model beam when the moment-curvature diagram is elastic-perfectly plastic [Fig. 1 $(f)$ ], with yield bending moment $M_{p l}$ the same for positive and negative curvatures, and with elastic bending stiffness $E I$. From equilibrium conditions, the bending moment distribution is a straight line with values $M_{1}$ at midspan and $M_{2}$ at spring supports of stiffness $C$ [Fig. 1(a)]; always $M_{2}=M_{1}-P L$. The beam is singly redundant, and the elastic solution yields $M_{1}=P L$ $(1+C L / 2 E D /(1+C L / E I)$, where $P=$ load [per half-beam; Fig. $1(a)$ ]; $L=$ length of half-beam; and $C=$ spring constant at support. For all the beams, we have $M \leq M_{1}$. Note also that $M_{2} \rightarrow 0$ for $C \rightarrow 0$ (the limit of a simply supported beam), and $M_{2} \rightarrow M_{1}$ for $C \rightarrow \infty$ (the limit of a fixed end beam).

Let $\boldsymbol{P}_{e l}$ be the largest value of $\boldsymbol{P}$ for which the whole beam is still elastic. This value occurs when $M$ under the load $P$ just reaches the plastic limit $M_{p l}$, i.e., $M_{1}=M_{p l}$, and so

$P_{e l}=\frac{1+\frac{C L}{E I}}{1+\frac{C L}{2 E I}} \frac{M_{p l}}{L}$

The plastic limit load is $P_{p l}=2 M_{p l} / L$ for $C>0$ and $M_{p l} / L$ for $C=0$ (for the case $C=0$, representing a simply supported beam, $P_{p l}$ as a function of $C$ is discontinuous). As the spring stiffness increases, the ratio $P_{e l} / P_{p l}$ increases from $1 / 2$ to 1 . This is a beneficial effect of bending moment redistribution, which reveals an enhanced carrying capacity of the structure compared to an elastic analysis. For strain-softening behavior, the strengthening effect of bending moment redistribution is partially suppressed, but it does not disappear completely. 
An engineer is interested to know exactly how much plastic strengthening and moment redistributions he can consider in design. To quantify these effects, we introduce the ductile strengthening factor:

$\mu_{1}=\frac{P_{\max }-P_{e l}}{P_{p l}-P_{e l}}$

and the redistribution ratio:

$\mu_{2}=1-\frac{\left|M_{1}-M_{2}\right|_{p}}{\left(M_{1}^{e l}-M_{2}^{e l}\right)}$

where $P_{\max }=$ the actual maximum load for the actual stress-strain diagram with strain softening; and $\left|M_{1}-M_{2}\right|_{p}=$ the magnitude of the corresponding difference of bending moments in presence of strain softening at maximum load. According to the elastic strength design $\mu_{1}=\mu_{2}=0$, while according to the plastic limit design $\mu_{1}=\mu_{2}=1$, which represents the case of full ductile strengthening and full redistribution. In the presence of strain softening we generally expect $0<\mu_{1}<1$ and $0<\mu_{2} \leq 1$. The moment at the ends can be either higher or less than the moment at midspan since the end of the beam may soften either before or after the midspan, depending on the mesh refinement, the value of the spring constant and the reinforcement.

In the presence of strain softening, we generally expect a partial rather than full redistribution and partial ductile strengthening (i.e $e_{i}, 0<\mu_{1}<1$ and $0<\mu_{2}<1$ ). As further characteristics, we may also introduce the following definitions:

1. The energy safety factor at load control:

$\mu_{3}=\frac{U_{p}}{U_{e l}}$

2. The total energy safety factor:

$\mu_{4}=\frac{U_{\max }}{U_{e l}}$

3. The ductility at load control:

$\mu_{s}=\frac{w_{p}}{w_{e l}}-1$

4. The ductility at displacement control:

$\mu_{6}=\frac{w_{\max }}{w_{e l}}-1$

where $U_{p}=$ the work done on the structure with the actual strain-softening properties to deform it up to the peak-load point [area 034 in Fig. 1(g)]; $U_{\max }=$ the total work to destroy the structure, equal to the entire area under the load-deflection curve until the load is reduced to zero; $U_{e l}=$ the maximum elastic energy calculated on the basis of the initial elastic modulus assuming that the maximum stress in the structure equals the strength $f_{t}^{\prime} ; w_{p}=$ deflection of the actual strain-softening structure at maximum load (peak point); $w_{e l}=$ deflection of the elastic structure with the initial elastic modulus when the maximum stress equals the strength $f_{t}^{\prime}$; and $w_{\max }=$ maximum stable deflection at displacement control. If the load-displacement diagram exhibits a snapback, $w_{\max }$ represents the deflection at snapback instability, i.e., when the strain-softening slope first becomes vertical.

Factors $\mu_{3}$ and $\mu_{4}$ are indications of the safety of the structure when the loading is primarily characterized in terms of energy, e.g., as in dynamic impact. The ductility factors are defined so that for elastic behavior their values approach zero (no ductility).

If the factors $\mu_{1}, \mu_{2}, \ldots$ could be approximately predicted for a structure of given properties, the full strain-softening load-deformation analysis would not have to be carried out. This would simplify design and make it possible to take advantage of the inelastic strain-softening behavior. Although we do not achieve such a goal in this paper, we attempt to make the first step, which is to develop an understanding of the dependence of these factors on structure size, relative support stiffness, shape of the stress-strain diagram, and so forth. Therefore, the layered finite element analysis of our model beam was run for many different combinations of structural and material properties, and the factors $\mu_{1}, \mu_{2}, \ldots$ were evaluated.

First we consider again the unreinforced beam in Fig. 1(a) with a symmetric curved strain-softening stress-strain diagram in Fig. 1(c). Fig. $2(d)$ shows the dependence of the moment redistribution factor $\mu_{2}$ on the structure size, particularly on beam length $2 L$ when the beam depth $h$ and the finite element size $L$ are kept constant $(2 L=N L)$. We see that the degree of moment redistribution declines as the structure size increases until a certain lower limit is reached. This limit corresponds to the load at which the maximum strain in the structure is equal to the strain at peak stress, i.e., to the load at the onset of strain softening. This limiting situation involves moment redistribution due to inelastic hardening behavior, which occurs before the peak stress. We see from this diagram that a higher degree of moment redistribution substantially strengthens the structure if the beam is not very slender.

Next we consider another stress-strain diagram shown in Fig. 1(d), in which the strain-softening occurs only in tension while compression is perfectly elastic. This behavior approximates concrete. The load-deflection diagrams for $E_{t} / E=-0.025$ and $E_{t} / E=-1$ are shown Fig. 3. As the strain-softening slope increases, the snapback instability occurs earlier. The effect is similar to that in Fig. $2(a)$. Figs. $4(a-b)$ show the dependence of the ductility strengthening factor $\mu_{1}$ and the redistribution ratio $\mu_{2}$ on the strain-softening slope $E_{t}$. We see that the steeper the material softening, the weaker is the ductile strengthening, and the lower is the redistribution, except for the small rise at the end of the curve in Fig. $4(b)$ due to numerical errors, caused by the fact that the accuracy at the peak depends on the load step and that the convergence is slow at this point. Figs. $4(c-d)$ show the dependence of the energy safety factors at controlled load and at 


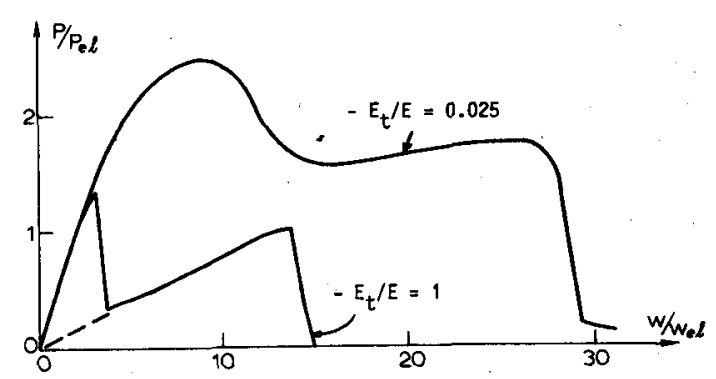

FIG. 3. Influence of Strain-Softening Siope on Load-Displacement Curve
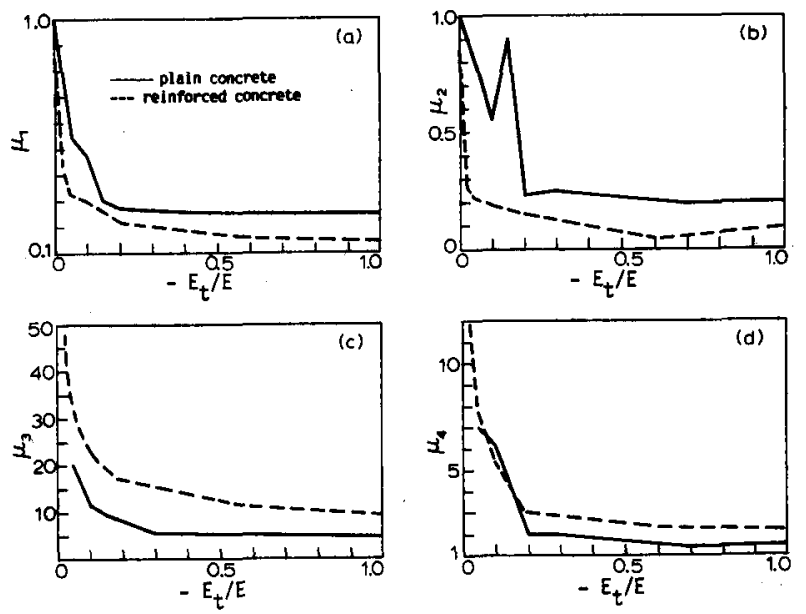

FIG. 4. (a) Influence of Strain-Softening Slope on Ductility Factor; (b) Redistrlbution Ratlo, and (o-d) Energy Safety Factors for Concrete and Reinforced Concrete Beams.

controlled displacement on the strain-softening slope. These factors also decline as the strain-softening slope $E_{t}$ becomes steeper.

Further, we carry out the layered finite element analysis for the reinforced beam shown in Fig. 1(b). Again, we assume the stress-strain diagram of concrete in the bilinear form; see Fig. 1(d). Figs. 4(a-d) show the dependence of the ductile strengthening factor, redistribution ratio, and the energy safety factors at controlled load and at controlled displacement on the strain-softening slope. Generally they decline as the slope gets steeper, although the redistribution ratio may show at the beginning a small increase.

Finally, we consider the same reinforced beam [Fig. 1(b)] with the trilinear stress-strain diagrams for compression and tension that have -elded plateaus of limited lengths and different strengths for tension and smpression [Fig. 1(e)]. An important characteristic of these diagrams is the ratio of the maximum plastic strain to the maximum elastic strain,

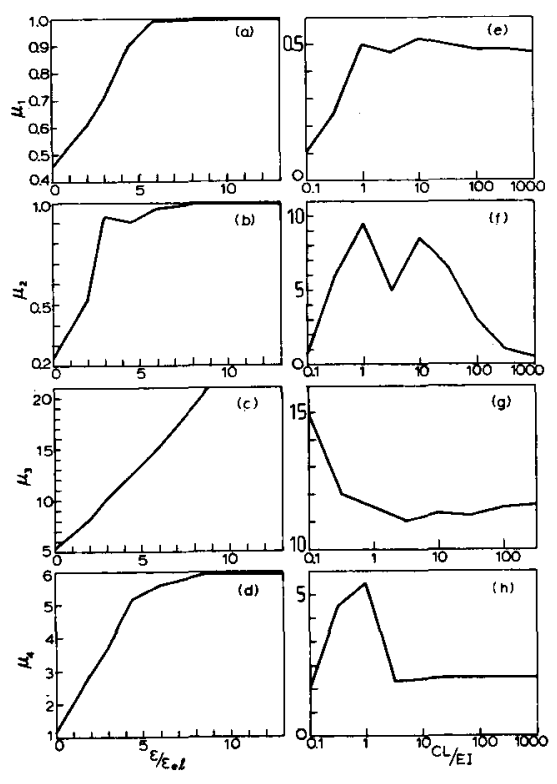

FIG. 5. (a- $a)$ Effect of Maximum Plastlc Strain and (e-h) Effect of Spring Constant on Ductility Factor, Redistribution Ratio, and Energy Safety Factors

$\varepsilon_{p l} / \varepsilon_{e l}$. The dependence of factors $\mu_{1}, \ldots \mu_{4}$ on this ratio is shown in Figs. $5(a-d)$. Generally, we see that all these factors increase as the plastic strain capacity of the material increases. The limits that are reached by the curves of $\mu_{1}, \mu_{2}$, and $\mu_{3}$ obviously correspond to the plastic solution according to limit analysis. So, a certain minimum value of the ratio $\varepsilon_{p l} / \varepsilon_{e l}$ is required for the applicability of limit analysis.

Figs. $5(e-h)$ show the dependence of factors $\mu_{1}, \ldots \mu_{4}$ on the nondimensionalized spring constant for the elastic restraints at the beam ends $\left(\varepsilon_{p l} / \varepsilon_{e l}=0.25 ; N=16\right)$.

The length of the reinforcing bars and the reinforcement ratio $\rho$ have a great influence on the response. Fig. 6 shows, for the reinforced beam of Fig. $1(b)$, the load-deflection diagrams for three different reinforcement arrangements. The effect of the reinforcement ratio $\rho$ on factors $\mu_{1}, \ldots \mu_{4}$ is shown in Figs. $7(a-d)$.

\section{SNAPBACK INSTABILITY}

A further important characteristic of response is the snapback instability, which is, however, rather difficult to determine by numerical step-bystep analysis [as mentioned before, Crisfield's arc-length method (13) could be used in that case, but programming would be complicated]. We attempt, therefore, to determine this instability analytically. One solution method will be in principle the same as that used in Ref. 11 for a strain-softening bar loaded uniaxially through a spring. This method is a variant of that used in Ref. 4 , in which a solution of the present kind of curvature localization instability of a strain-softening beam with elastic end 


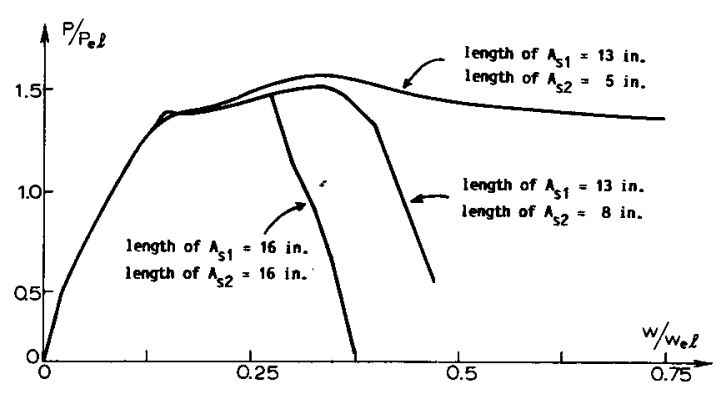

FIG. 6. Influence of Reinforcing Bars on Load-Displacement Curve
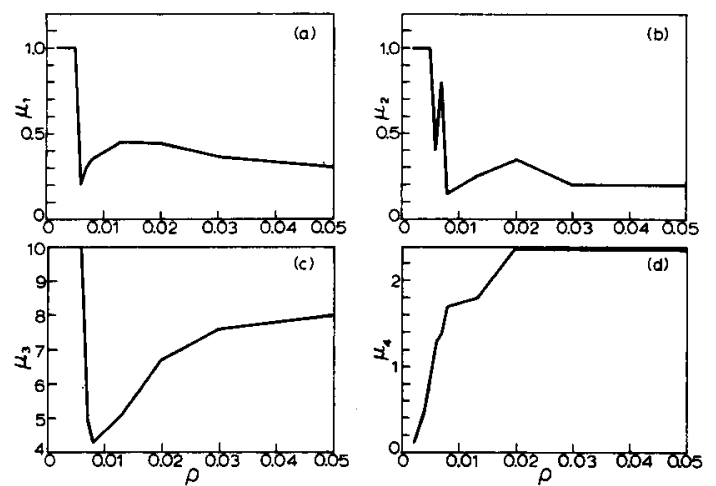

FIG. 7. Influence of Relnforcement Ratio on: (a) Ductility Factor. (b) Redistribution Ratio; (o-d) Energy Safety Factors

restraints was obtained. (However, load control rather than displacement control was assumed in that study to exist during the instability, for the sake of simplification.)

In similarity to the crack-band theory (9), we must assume, as already mentioned, that curvature cannot localize into a segment shorter than a certain minimum length, $2 l$ [Fig. $8(a)$ ]. In such a strain-softening segment, the bending moment $M$ and curvature $\kappa$ may be characterized only by their averages and may thus be assumed to be uniformly distributed throughout the strain-softening segment. This assumption avoids introduction of averaging integrals over segment $2 l$, which would otherwise be required by a strict application of the nonlocal continuum theory $(8,12,27)$. Accordingly, we assume that the actual bending moment distribution is replaced, for the purpose of curvature calculation, by a distribution with a constantmoment segment of length $2 l$ in the middle of the beam, such that the area under the bending moment diagram remains unchanged (this preserves the rotation difference between the ends of this segment); see Fig. $8(b)$. Furthermore, for the sake of simplification, we assume that within the strain-softening segment, as well as outside it, the incremental bending rigidities $R_{t}$ and $R_{u}$ for further loading and unloading are distributed uniformly. According to the layered finite element model, they are, of
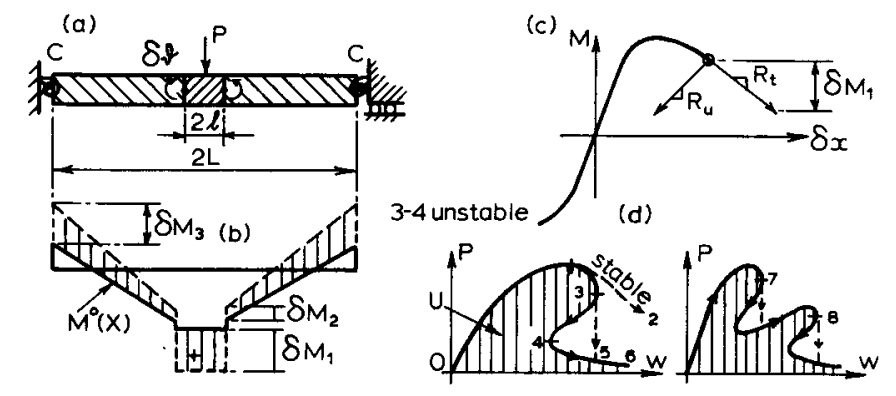

FIG. 8. Stability Analysis: (a-b) Definition of Curvature Localization Zone and (c) Average Bending Rigidities; (d) Snapback Instability

course, variable throughout these segments, but now we replace them with their average values $R_{t}$ and $R_{u}$ [Figs. 8(b-c)].

To determine instability, we consider infinitesimal variations $\delta M(x)$ and $\delta \kappa(x)$ of the bending moment and curvature, superimposed on a certain initial state of beam, which is characterized by the initial bending moment $M^{0}(x)$ and initial curvature $\kappa^{0}(x)$. The load-point deflection, $w$, is fixed during the variation $(\delta w=0)$, and the load $P$, representing a reaction, can change arbitrarily. As in Ref. 4 , we assume that small variations $\delta \theta$ of rotation are enforced at the ends of the curvature localization segment of length $2 l$ [Figs. $8(a-d)$ ]. We try to calculate the applied moment reactions $\delta M$ at these points and the work done by these moment reactions. The bending moment variations are characterized by variation $\delta M_{1}$ within segment $2 l, \delta M_{2}$ just outside it, and $\delta M_{3}$ at the beam ends. From $\delta M_{2}$ to $\delta M_{3}$, the bending moment varies linearly, and at the ends of segment $2 l$, there are jumps of magnitude $\delta M$ [Fig. $8(b)$ ], i.e., $\delta M_{1}=\delta M_{2}+\delta M$. For the strain-softening segment we have $\delta \theta=\delta M_{1} l / R_{t}$. Applying the virtual work principle and integrating along segments $l$ and $L-l$, we find that the conditions of zero variations of the rotation and of the deflection at the midspan are

$\delta \theta+\frac{L-l}{2 R_{u}}\left(\delta M_{2}+\delta M_{3}\right)+\frac{\delta M_{3}}{C}=0$

$\frac{(L-l)^{2}}{6 R_{u}}\left(\delta M_{3}+2 \delta M_{2}\right)+\frac{l\left(L-\frac{l}{2}\right)}{R_{t}} \delta M_{1}=0$

By substitution of $\delta M_{1}=\delta M_{2}+\delta M$ and algebraic elimination of $\delta M_{2}$ and $\delta M_{3}$, Eqs. 8-9 can be reduced to a single relation, $\delta M=k \delta \theta$, in which the incremental stiffness $k$ is given as $k=2 k R_{u}^{2} l l$, with

$\bar{k}=\frac{2 \frac{R_{t}}{R_{u}}+6 \frac{l\left(L-\frac{l}{2}\right)}{(L-l)^{2}}\left(\frac{1}{C}+\frac{L-l}{2 R_{u}}\right)-\frac{l}{R_{u}}-\frac{R_{t}(L-l)}{R_{u}^{2}}}{\frac{4 R_{u}}{C}+(L-l)}$ 


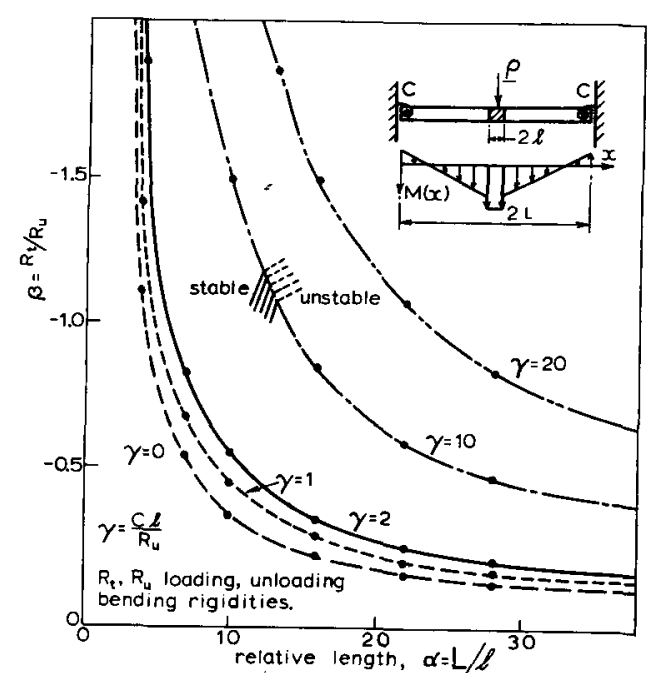

FIG. 9. Influence of Relative Length and Spring Constant on Stabllity Limit

The variation of the load during the instability mode may be calculated as $\delta P=\left(\delta M_{2}-\delta M_{3}\right) /(L-l)$. The work done on the structure by enforcing the rotations $\delta \theta$ is $\Delta W=\delta M \delta \theta / 2=k(\delta \theta)^{2} / 2$. If $\delta W>0$, the structure is stable, i.e., the deformation increments will not occur if work $\Delta W$ is not supplied. However, if $\Delta W<0$, the structure is unstable because a kinematically admissible deformation variation releases energy. Such deformation variation must happen spontaneously according to the second law of thermodynamics. Thus, $\Delta W<0$ indicates instability and $\Delta W=0$ the critical state. It follows that $k>0$ signifies a stable state, $k<0$ an unstable state, $k=0$ a critical state.

Numerical evaluations of Eq. 10 have been used to obtain the stability limits. The results, plotted in Fig. 9, show the lines of critical $R_{t} / R_{u}$ values as functions of the relative beam size for various fixed values of $C L / R_{u}$, and of the relative stiffness of the elastic restraints at beam ends. The states below these lines are stable, and the states above these lines are unstable. We see that with an increasing size of the beam or with a decreasing stiffness of the end restraint, the magnitude of $R_{t} / R_{u}$ for the critical state decreases, which means that instability occurs closer to the peak point of the moment-curvature diagram (or to the peak point of the load-deflection diagram). The diagrams in Fig. 9 permit an approximate assessment of instability of our model beam (approximate because $R_{t}$ and $R_{u}$ are assumed to be uniformly distributed within each segment).

In previous works (Refs. 2,3,14-18,21-25), by analogy with plastic limit analysis, the softening was assumed to be localized in a hinge (a point). Let us examine whether this simplifying assumption makes a significant difference. Consider the beam in Fig. 10 and assume that, at midspan, there is a softening hinge such that its rotation $\Delta \theta$ caused by the bending moment $M$ equals the rotation difference between the ends of the segment

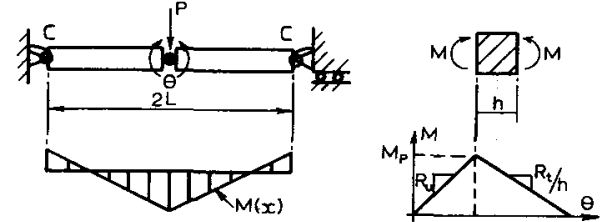

FIG. 10. Sottening Hinge Analysis, Moment-Rotation Curve

of length $2 l=h$, caused by moments $M$ applied at the ends, minus the elastic rotation. This yields for the hinge the moment-rotation relation:

$\delta \theta=\frac{M_{p}-M}{C_{t}}$

with $\frac{1}{C_{t}}=-h\left(\frac{1}{R_{u}}-\frac{1}{R_{t}}\right)$

We may now repeat the same analysis as before, except that the segment of length $2 l$ is replaced by a point hinge characterized by Eqs. 11 $a-b$. Imagining the moments $\delta M$ to be applied at the hinge, we obtain the relation $\delta M=\kappa^{*} \delta \theta$ in which the incremental stiffness now is

$$
\kappa^{*}=C_{t}+\frac{2+\frac{6 R}{C L}}{\frac{1}{2 R_{u}}+\frac{2}{C}}
$$

The stability limits according to this equation are plotted in Fig. 11 (for various $C$ ) as the solid lines.

For comparison, Fig. 11 also shows as the dashed lines the stability limits for a strain-softening segment that has the length $2 l=h$ and the same secant stiffness at uniform moment distribution as the hinge with the elastic segments of lengths $l+l$ adjacent to it.

For a small $C$, as the softening region becomes short with respect to the length of the beam, the agreement is close to excellent. However, when the slenderness of the beam decreases, the difference of the present calculation from the classical analysis (i.e., a softening point-hinge) becomes significant. Finally, for high values of the spring constant $C$, it becomes large. In these cases, the failure analysis based on a softening hinge would be inadequate.

On the load-deflection diagram, the present type of instability, called the snapback instability, represents the point at which the descending slope of the load-deflection diagram becomes vertical (point 3 in Fig. 8). This is clear if we note that the instability involves load variation $\delta P$ at constant midspan deflection $w$. If the beam is not sufficiently long, or the end restraints are not sufficiently weak, the load-deflection diagram may exhibit no snapback stability [diagram 012 in Fig. 8(d)]. Otherwise, snapback instability occurs, and the load-deflection diagram after the point of instability descends at a positive slope; see segment 34 in Fig. 8(d), at 


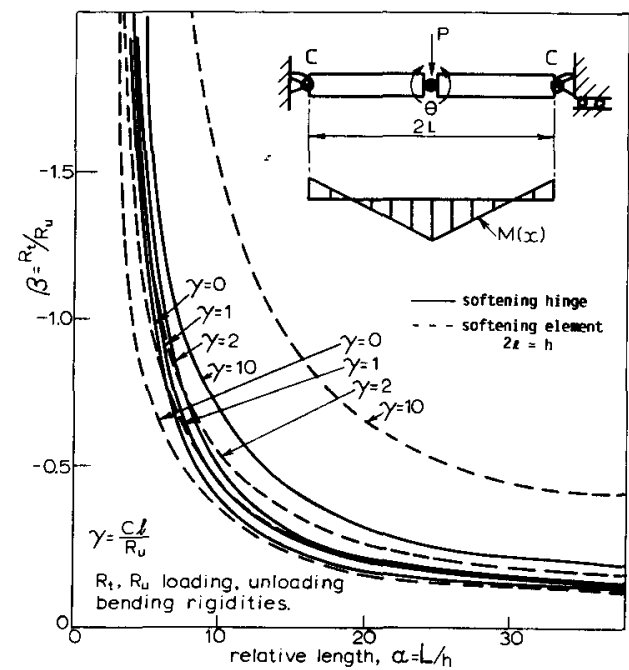

FIG. 11. Stability Limits for Sottening Hinge Analysis, in Comparison with Softening Element Analysis

which the equilibrium is unstable. Under displacement controlled conditions, the structure snaps dynamically from 3 to 5 . Nevertheless, the knowledge of the equilibrium path 013456 [Fig. 8(d)] is important; the area under the curve (cross-hatched in Fig. 8) represents the energy dissipated by the structure. The energy corresponding to area 345 is transformed to kinetic energy along path 35 , and subsquently is dissipated as heat due to damping. The fact that strain softening may cause snapback in beams was shown by Mróz (26) and was also implied in Ref. 4.

Note that without imagining the bending moment to be uniformly distributed wihin segment $2 l$, one could not explain how strain softening could spread from the midspan point into a segment of finite length, which is known as Wood's paradox (30). However, if strain softening is confined to the midspan cross section, the energy dissipation during failure of the structure is zero, since the strain-softening volume is zero and the energy dissipation per unit volume is finite. This is one reason that a rigorous formulation should be nonlocal and that in our approach a strain-softening segment of finite length must be assumed.

As already experienced numerically (Fig. 2), a statically indeterminate structure may exhibit more than one point of snapback instability. This is illustrated by points 7 and 8 in Fig. 8(e). One can associate each snapback instability with curvature localization in one strain-softening (hinging) region of the beam. Since an $n$-times redundant structure can fail plastically at most with $n+1$ yield hinges, the strain-softening response of the same structure may exhibit at most $n+1$ snapback points. Thus, for our model beam, whose degree of redundancy is 2 , there can be at most three snapback instabilities, and two if the deformation is symmetric.

\section{Conclusions}

1. When the element size is refined to zero, strain-softening material models lead to physically meaningless solutions for which the energy dissipated at failure tends to zero.

2. One must impose a certain minimum length of the strain-softening segment of the beam, which must be considered to be a cross section property. It may approximately be taken to be equal to the beam depth.

3. The basic types of strain-softening effects in statically indeterminate structures may be characterized by the ductile strengthening factor, the moment redistribution ratio, the energy safety factor and the ductility factor, as defined in Eqs. 2-7. The ductility factor is determined by the point of snapback instability on the load-deflection curve.

4. The response of the structure is strongly influenced by its size, the end-restraint stiffness, the strain-softening slope $E_{t}$, and the length of the yield plateau.

5. The occurrence of instability under displacement control, i.e., snapback instability, can be approximately determined by checking when the incremental stiffness expression in Eq. 10 changes from negative to positive.

6. A statically indeterminate strain-softening structure of redundancy degree $n$ can exhibit at most $n+1$ points of snapback instability. It will exhibit all these snapbacks if it is sufficiently slender, or if the postpeak strain-softening slope is sufficiently steep. Finite element analysis would encounter all these snapback instabilities if the finite elements were sufficiently small (regardless of the value of the strain-softening slope $E_{t}$ ). However, arbitrarily small finite elements are prohibited according to conclusion 2.

7. In general, the strain-softening segment of a beam cannot be replaced, for the purpose of calculations, by a softening hinge. This replacement is possible only for sufficiently slender beams.

\section{Acknowledgment}

Partial financial support under United States National Science Foundation Grant No. MSM-8700830 to Northwestern University is gratefuly appreciated.

\section{Appendix. References}

1. ACI 328-83 (1983). "Building code requirements for reinforced concrete." American Concrete Institute, Detroit, Mich.

2. Baker, A. L. L., and Amarakone, A. M. N. (1964). "Inelastic hyperstatic frames analysis." Proc. Int. Symp. on the Flexural Mech. of Reinforced Concrete, American Concrete Institute Special Publication No. 12, Miami, Fla., 85-142.

3. Barnard, P. R. (1965). "The collapse of reinforced concrete beams." Proc. Int. Symp. Flexural Mech. of Reinforced Concrete, held in Miami, Fla. American Concrete Institute Special Publication No. 12, Detroit, Mich., 5-1-520.

4. Bažant, Z.P. (1976). "Instability, ductility and size effect in strain-softening concrete." J. Engrg. Mech. Div., ASCE, 102(2), 331-334, with closure Vol. 103 pp. 357-358, 775-777; based on Struct. Eng. Report No. 74-8/640 
Northwestern University, August 1974

5. Bažant, Z. P. (1984). "Size effect in blunt fracture: Concrete, rock, metal." J. of Engrg. Mech., ASCE, 110(4), 518-535.

6. Bažant, Z. P. (1985). "Fracture mechanics and strain-softening of concrete." Proc. U.S.-Japan Seminar on Finite Element Analysis of R. C. Struct., held in Tokyo, Japan, ASME, New York, C. Meyer and H. Okamura, eds., American Society of Mechanical Engineers, New York, N.Y., 121-150.

7. Bažant, Z. P. (1986). "Mechanics of distributed cracking." Applied Mech. Rev., ASME, 40(2), 675-705

8. Bažant, Z. P., Belytschko, T. B., and Chang, T. P. (1984). "Continuum theory for strain-softening." J. Engrg. Mech., ASCE, 110( ), 1666-1692.

9. Bažant, Z. P., and Oh, B. H. (1983). "Crack-band theory for fracture of concrete." Matériaux et constructions, 16(32), 155-177.

10. Bažant, Z. P., Pan, Y., and Pijaudier-Cabot, G. (1986). "Softening in reinforced concrete beams and frames." Report No. 86-7/428s, Center for Concrete and Geomaterials, Northwestern Univ., Evanston, Ill.

11. Bažant, Z. P., and Panula, L. (1978). "Statistical stability effects in concrete failure." J. Engrg. Mech., ASCE, 104(5), 1195-1212.

12. Bažant, Z. P., and Pijaudier-Cabot, G. (1987). "Modeling of distributed damage by nonlocal continuum with local strain." Proc., 4th Int. Conf. on Numer. Meth. Fracture Mech., A. P. Luxmoore, R. J. Owen and M. F. Kanninen, eds., held in San Antonio, Tex., Pineridge Press, Swansea, U.K., 411-423.

13. Crisfield, M. A. (1983). "An arc-length method including line searchers and accelerations." Int. J. of Numer. Meth. Engrg., 19, 1269-1289.

14. Darvall, P. LeP. (1984). "Critical softening of hinges in nortal frames." $J$. of Struct. Engrg., ASCE, 110(1), 157-162.

15. Darvall, P. LeP. (1983). "Critical softening of hinges in indeterminate beams and portal frames". Civ. Engrg. Trans., CE25(3), I. E. Australia, Clayton, Australia, 199-210.

16. Darvall, P. LeP. (1983). "Some aspects of softening in flexural members." Res. Report 3/1983, Dept. of Civ. Engrg., Monash Univ., Clayton, Australia.

17. Darvall, P. LeP., and Mendis, P. A. (1985). "Elastic-plastic-softening analysis of plane frames." J. of Struct. Engrg., ASCE, 111(4), 871-888.

18. Ghosh, S. K., and Cohn, M. Z. (1972). "Nonlinear analysis of strain-softening structures." Inelasticity and nonlinearity in structural concrete. M. Z. Cohn, ed., Study No. 8, Univ. of Waterloo Pres, Waterloo, Ontario, Canada, 315-332.

19. Hand, F. R., Pecknold, D. A., and Schnobrich, W. C. (1973). "Nonlinear rayered analysis of RC plates and shells." J. Struct. Div., ASCE, 99(7), 14911505.

20. Lin, C. S., and Scordelis, A., (1975). "Nonlinear analysis of RC shells of general form." J. Struct. Div., ASCE, 101(3), 523-538.

21. Maier, G. (1967). "On elastic-plastic structures with associated stress-strain relations allowing for work softening." Meccanica, 2(1), 55-64.

22. Maier, G. (1967). "Extremum theorems for the analysis of elastic plastic structures containing unstable elements." Meccanica, 2(4), 235-242.

23. Maier, G. (1971). "Incremental plastic analysis in the presence of large displacements and physical instabilitizing effects." Int. J. of Solids and Struct., 7, 345-372.

24. Maier, G., Zavelani, A., and Dotreppe, J. C. (1973). "Equilibrium branching due to flexural softening." $J$. of Engrg. Mech. Div., ASCE, 99(4), 897-901.

25. Maier, G. (1971). "On structural stability due to strain-softening." IUTAM Symp. on Instability of Continuous Systems, held at Herrenhalb, Germany, Sept., 1969, Springer-Verlag, West Berlin, Germany, 411-417.

26. Mróz, Z. (1985). "Current problems and new directions in mechanics of geomaterials." Chapter 24, Mechanics of geomaterials: Rocks, concretes, soils, Z. P. Bažant, ed., John Wiley and Sons, Chichester, England, New York, N.Y., 534-566,
27. Pijaudier-Cabot, G., and Bažant, Z. P. (1986). "Nonlocal damage theory." Report No. 86-8/428n, Northwestern Univ., Evanston, Ill.

28. Schnobrich, W. C. (1982). "Concrete cracking." Finite element analysis of reinforced concrete (state-of-the-art report), Chapter 4, ASCE, New York, N.Y., 204-233.

29. Warner, R. F. (1984). "Computer simulation of the collapse behavior of concrete structures with limited ductility." Proc. Int. Conf. Computer-Aided Analysis and Design of Concrete Struct., held in Split, Yugoslavia, F. Damjanic, E. Hinton, et al., eds., Pineridge Press, Swansea, England, 1257-1270.

30. Wood, R. H. (1968). "Some controversial and curious developments in the plastic theory of structures." Engineering plasticity. J. Heyman and F. A. Leckie, eds., Cambridge, Univ. Press, Cambridge, England, 665-691. 